\title{
PRODUÇão CIENTíFICA, PÓS-GRADUAÇÃO E A RAMB
}

Está ocorrendo um aumento significativo na produção científica do Brasil na área de saúde. Se considerarmos os artigos indexados no Institute for Scientific Information (ISI), o percentual em relação ao mundo passou de 0,88\%, em 1996, para I,73\%, em 2004 !.

Quando comparados os qüinqüênios | 98 | - 1985 e 1997 200 I, houve aumento de quatro vezes na produção científica brasileira, com crescimento de 5,3 vezes no percentual de artigos citados e de I,8 vezes no índice de impacto das publicações. Na área específica da medicina, $52,8 \%$ dos artigos publicados no qüinqüênio | 997-200 | foram citados, e o índice de impacto médio das publicações foi de 2,8 vezes $^{2}$. O crescimento da produção na área de saúde colocou o Brasil como uma das 20 nações mais produtivas em ciências da saúde na última década ${ }^{3}$.

Entre as 20 instituições que mais publicaram nas áreas de saúde e ciências biológicas, o crescimento no volume de publicações entre os triênios de | 998-2000 e 200 |-2003 variou de I 5\% a 23 | \%, na base Medline, e de $21 \%$ a $231 \%$, na base ISI. Mais importante, talvez, foi o crescimento do número de publicações por orientador dos programas de pós-graduação destas instituições. Entre os diferentes triênios, foiverificado um crescimento de $10 \%$ até $84 \%{ }^{4}$.

Estes números são distintos da observação em uma destas unidades, em que mais de $50 \%$ dos recém-doutores da década de 1990 permaneciam sem nenhuma publicação até cinco anos após a defesa $^{5}$

Uma das possíveis explicações para este fenômeno está na avaliação dos programas de pós-graduação. A metodologia e os critérios de avaliação dos programas stricto sensu foram reformulados a partir de 1997. O processo está em constante evolução e os critérios de avaliação trienal vêm sendo constantemente reavaliados pela CAPES (Coordenadoria de Aprimoramento do Pessoal de Ensino Superior), por meio de suas comissões de área. Estas comissões são formadas por diferentes docentes, de diferentes programas de pós-graduação, de todo o país. Para o triênio 2004 2007, por exemplo, os critérios incluíram:

I - Proposta do programa, em que se avaliam coerência, consistência, abrangência e atualização das áreas de concentração, linhas de pesquisa e projetos em andamento; coerência, consistência e abrangência da estrutura curricular e infra-estrutura para ensino, pesquisa e extensão.

2- Corpo docente, em que se avaliam formação, adequação da dimensão, composição e dedicação dos docentes permanentes de cada programa; perfil, compatibilidade e integração do corpo docente permanente com a proposta do programa; atividade docente e distribuição de carga letiva entre os docentes permanentes; participação dos docentes nas atividades de ensino e pesquisa na graduação, quando pertinente, e participação em pesquisa e desenvolvimento de projetos.

3 - Corpo discente, teses e dissertações, em que se avaliam o número de orientações de teses e dissertações concluídas no período, em relação ao corpo docente permanente eà dimensão do corpo discente; adequação e compatibilidade da relação orientador/ discente; participação de discentes autores da pós-graduação e, quando pertinente, da graduação, na produção científica do programa; qualidade das teses e dissertações, por meio do número vinculado à publicações, e eficiência do programa na formação de mestres e doutores, por meio do tempo de formação de mestres e doutores e percentual de bolsistas da Capes e do CNPq titulados.

4 - Produção intelectual, em que se avaliam o número de publicações qualificadas do programa, por docente permanente, e a distribuição de publicações qualificadas em relação ao corpo docente do programa.

5 - Inserção social, em que se avaliam inserção, presença e relevância do programa, além da visibilidade do mesmo

Dentro destes critérios, o item 4, produção intelectual, estabelece que para um programa excelente (conceito 7), pelo menos $80 \%$ de seu corpo docente permanente deve ter seis ou mais artigos em periódicos qualificados como Qualis Internacional A ou B (artigos da base ISI classificados de acordo com seu fator de impacto), sendo que pelo menos três sejam em Qualis Internacional A. Para obter um conceito bom, $80 \%$ dos docentes permanentes devem ter, no triênio, três ou mais artigos em periódicos classificados como Qualis Nacional A (periódicos da base Scielo) ou superior, sendo que pelo menos um seja em Qualis Internacional C (revistas presentes na base Medline) ou superior ${ }^{6}$.

Possivelmente, esta pressão por publicações de excelência tem contribuído para o crescimento expressivo do número de jornais e revistas daárea médica em nosso país com visibilidade internacional. Temos hoje pelo menos 16 revistas brasileiras da área de saúde indexadas na base Medline e 64 indexadas na base Scielo. Na base ISI, temos atualmente 27 jornais, de diferentes áreas, indexados. A RAMB está indexada nas três bases, sendo hoje considerada na área da saúde da CAPES como Qualis Internacional B. Acreditamos que esta excelente posição de nossa revista nas bases de indexação internacionais deva ser um estímulo para a busca deste veículo na publicação de resultados de pesquisa, sejam provenientes de pósgraduações ou não.

Temos procurado fazer a nossa parte neste cenário. No mês de novembro, entrou em funcionamento o novo site para submissão de artigos. Mais simples e ágil, tanto para os autores como para o corpo editorial, o novo sistema pretende facilitar o trabalho de ambos. Algumas ferramentas, como a procura automática de artigos publicados em periódicos Scielo com as mesmas palavras chave do artigo em questão, devem estimular a citação e contracitação de artigos nacionais. O tempo de resposta, considerado pelos editores da RAMB como um ponto fundamental, ainda precisa ser melhorado. No caso de resposta negativa, este tempo é, em média, de I 4 dias. Entretanto, quando o artigo é aceito e obrigatoriamente provém de uma revisão mais detalhada e criteriosa, atingimos uma média de 300 
dias, que consideramos inaceitável. O novo sistema, mais fácil, e a inclusão de um amplo corpo de revisores, atualizado recentemente, devem melhorar este panorama.

Atualmente, de cada quatro artigos submetidos à RAMB, apenas um é publicado. ARAMB espera mostrar a todos o que há de novo na ciência médica do Brasil. Que as inovações que preparamos na RAMB façam com que o seu seja o próximo artigo aprovado.

Daniel Deheinzelin Bruno Caramell

Referências

I. Ministério da Ciência e Tecnologia. Brasil: Artigos publicados em periódicos científicos internacionais indexados no Institute for Scientific Information (ISI) e percentual em relação ao mundo, I98|-2004. [citado 2 out 2007]. Disponível em:

http://www.mct.gov.br/index.php/content/view/57 I I.html.

2. Guimarães JA. A pesquisa médica e biomédica no Brasil. Comparações com o desempenho científico brasileiro e mundial. Cienc Saúde Coletiva. 2004; 9:303-27.

3. Paraje G, Sadana R, Karam G. Public health. Increasing international gaps in health-related publications. Science. 2005;308:959-60.

4. Zorzetto R, Razzouk D, Dubugras MTB,Gerolin J, Schor N, Guimarães JA, et al. The scientific production in health and biological sciences of the top 20 Brazilian universities. Braz J Med Biol Res. 2006;39:|513-20.

5. Younes RN, Deheinzelin D, Birolini D. Graduate education at the faculty of medicine of the University of Sao Paulo: quo vadis? Clinics. 2005;60:6-8.

6. Ministério da Educação. Coordenação de Aperfeiçoamento de Pessoal de Nível Superior. Capes. Qualis. [citado 2 out 2007]. Disponível em: http:// www. capes.gov.br/avaliacao/webqualis.html. 